\title{
ISOLATION AND IDENTIFICATION OF PHYTOSTEROLS FROM BIGNONIA VENUSTA (L.)
}

\author{
MANOJ SHARMA*, MUKESH KUMAR KHICHAR, AGRAWAL RD
}

Department of Botany, Mycology and Plant Pathology Lab, University of Rajasthan, Jaipur, Rajasthan, India. Email: manojsharma9680@gmail.com

Received: 28 June 2017, Revised and Accepted: 04 September 2017

\section{ABSTRACT}

Objective: To isolate phytosterols from Bignonia venusta (L.) and its antimicrobial activity.

Introduction: $B$. venusta is an important medicinal plant known for its vast potential. It is a valuable plant which is commonly used in traditional system of medicine for relieving pain and inflammation, as well as in a number of metabolic disorders such as diabetes and obesity.

Methods: In the present study, phytosterols from B. venusta was identified and quantified in vivo. Phytosterols were identified using chromatographic and spectral studies.

Results: Trimethyl (3,3-difluoro-2-propenyl) silane, butanoic acid, 3-methyl-3-nitroso-, methyl ester, peroxide, dibutyl, and 1,2-epoxy-5,5-dimethyl1-phenyl-3-hexyne were identified by infrared and gas chromatography-mass spectroscopy (GC-MS). GC-MS profiling showed various compounds. It is the first report on phytosterols from the experimental plant. Further, we studied antimicrobial potential of isolated compounds against clinically important microbes.

Conclusion: B. venusta (L.) is an ideal source of phytosterols and act as antimicrobial agent.

Keywords: Bignonia venusta L., Infrared, Gas chromatography-mass spectroscopy, Phytosterols.

(C) 2017 The Authors. Published by Innovare Academic Sciences Pvt Ltd. This is an open access article under the CC BY license (http://creativecommons. org/licenses/by/4. 0/) DOI: http://dx.doi.org/10.22159/ajpcr.2017.v10i12.21009

\section{INTRODUCTION}

Today's health-care systems rely largely on plant materials. Much of the world's population depends on traditional medicine to meet daily requirements, especially in developing countries. The use of plantbased remedies is also widespread in many developed countries, and pharmaceuticals are based or devised from plants or plant products [1]. Plant sterols are triterpenes that are important structural components of plant membranes, and free phytosterols serve to stabilize phospholipid bilayers in plant cell membranes just as cholesterol does in animal cell membranes [2]. Plant sterols structurally similar to cholesterol that act in the intestine to lower cholesterol absorption. Since they have very low systemic absorption and are already present in healthy diets, increasing the intake of phytosterols may be a practical way to reduce coronary heart disease with minimum risk [3]. Studies now show that phytosterols consumption, of about $2 \mathrm{~g} /$ day, results in an approximately $9 \%$ reduction in low-density lipoprotein-cholesterol, which is the "bad" cholesterol known to contribute to heart disease.

Bignonia venusta is a neotropic evergreen vine widely distributed in southern Brazil. Native Brazilians use the aerial parts of B. venusta for the treatment of cough and flu. They administer its decoction orally as a general tonic and also as an infusion to treat diarrhea, vitiligo, and jaundice [4-6]. Tonics made from the stems of this plant are useful for the treatment of diarrhea, whereas flower preparations have been shown to attenuate vomiting [6]. Chemical investigations have shown that methanolic extracts of the roots of $B$. venusta contain allantoin, steroids, flavonone hesperidin (4,7-0-b-D-rutinosil-3',5- dihydroxy-4'methoxyiflavanona), and 3-b-b-D-glicopiranosilsitosterol (4). Similar observations regarding the isolation of n-hentriacontan (n-C31H64) 7-0-b-D-glicopiranosilacacetina), meso-inositol (myoinositol) as well as several amino acids and sugars have been observed in the flowers [6].

The development of antibiotic resistance in pathogenic bacteria is a major public health concern [7]. The use of plants and plant products as medicines could be traced as far back as the beginning of human civilization [8]. Plants are important source of drugs, especially in traditional medicine [9].

It is estimated that plant materials are present in, or have provided models for $50 \%$ Western drugs [10], many commercially proven drugs used in modern medicine were initially used in crude form in traditional or folk healing practices, or for another purpose that suggested potentially useful biological activity [10]. The primary benefits of using plant derived medicines are that they are relatively safer than synthetic alternatives, offering profound therapeutic benefits, and more affordable treatment [11]. Much of the exploration and utilization of natural products as antimicrobial arise from microbial sources.

Through most of the clinically used antibiotics are produced by soil microorganisms or fungi, higher plants have also been a source of antibiotics [12]. Plant-based antimicrobials represent a vast untapped source of medicines. Continuous and further exploration of plant antimicrobials is of the increase. They are effective in the treatment of infectious diseases while simultaneously mitigating many of the side effects that are often associated with synthetic antimicrobials [13] and the use of phytochemical products and plant extracts as resistance modifying agents represents an increasingly active research topic [13].

\section{METHODS}

Collection and identification of plant materials

Fresh plant materials (leaf and bark) of B. venusta were collected from Department of Botany, University of Rajasthan India. The plant materials were taxonomically identified and authenticated by Department of Botany, University of Rajasthan (RUBL 211623), Jaipur. The plant materials were cleaned, shade dried, and pulverized to powder in a mechanical grinder. The powdered materials were stored in airtight containers till use. 


\section{Extraction}

Dried and powdered plant material (both leaves and stem) was air dried and hydrolyzed in $30 \% \mathrm{HCl}(\mathrm{v} / \mathrm{v})$ for $4 \mathrm{hrs}$. Each hydrolyzed sample was washed with distilled water till $\mathrm{pH} 7$ was achieved and was dried later. The dried preparation was again extracted with benzene for $24 \mathrm{hrs}$. The extract was filtered and dried in vacuo. The crude extract was dissolved in benzene before chromatographic examination [14].

\section{Thin layer chromatography (TLC)}

Glass plates coated with silica gels $G$ were used. Each of the extract was cochromatographed separately with authentic sterols as marker. These plates were developed in an airtight chromatographic chamber, saturated with solvent mixture (hexane:acetone:8:2) [15]. Other solvents such as benzene and ethyl acetate (85:15) [16]. Benzene:ethyl acetate (3:1), was also used but hexane:acetone (8:2) gave better separation. These plates were air dried and visualized under ultraviolet (UV) light, and fluorescent spots corresponding to that of standards marker were marked. These developed plates were sprayed with $50 \%$ sulphuric acid [17] and anisaldehyde reagent, separately, and heated at $110^{\circ} \mathrm{C}$ for 10 minutes.

\section{Preparative TLC (PTLC)}

PTLC was performed using silica gel G coated plates $(0.4-0.5 \mu \mathrm{m})$ along with the reference markers. These plates were developed in hexane:acetone (8:2), air dried and examined under UV light. Each spot coinciding with that of standard marker was marked, scraped from 50 plates, and eluted with chloroform. The eluted reactions were subjected to crystallization, separately, and their melting point, mixed melting point were determined. The isolated compounds were also subjected to UV and infrared (IR) spectral studies.

\section{Identification}

Melting point and IR spectra of each of the isolated compounds (leaves) was taken and a comparison of the TLC color reaction was made, which was found to be in accordance with that of studied authentic compounds.

\section{Antimicrobial activity}

Antimicrobial activity of phytosterols from B. venusta (L.) was studied. Four bacterial and fungal strains were selected for the primary screening

\section{Microorganisms used}

Clinical laboratory bacterial isolates of, Staphylococcus aureus (MTCC-3381), Bacillus subtilis (MTCC-10619), Escherichia coli (MTCC-443), and Streptomyces grisveus (MTCC-4734) fungal isolates, namely, Aspergillus niger (ATCC-9029), Fusarium oxysporium (ATCC-62506), Trichoderma reesei (ATCC-13631), and Penicillium funicolusum (ATCC-11797) were collected from the stock cultures of Microbiology Laboratory, SMS Medical College, Jaipur, India.

\section{Preparation of extract}

The isolated samples were dissolved in their respective solvent for further studies.

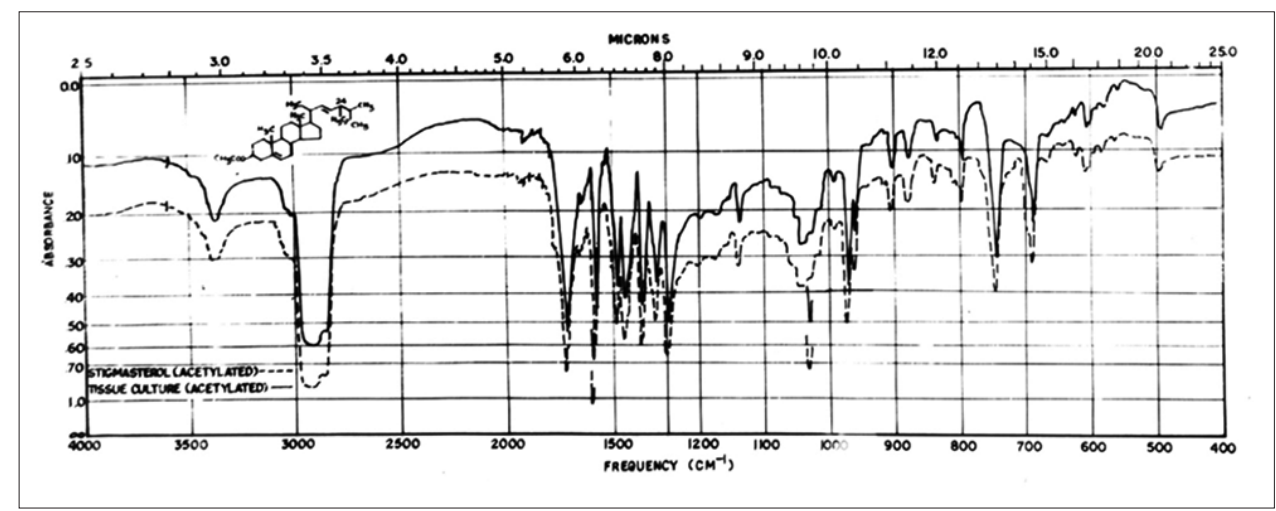

Fig. 1: Infrared spectra of isolated and standard stigmasterol

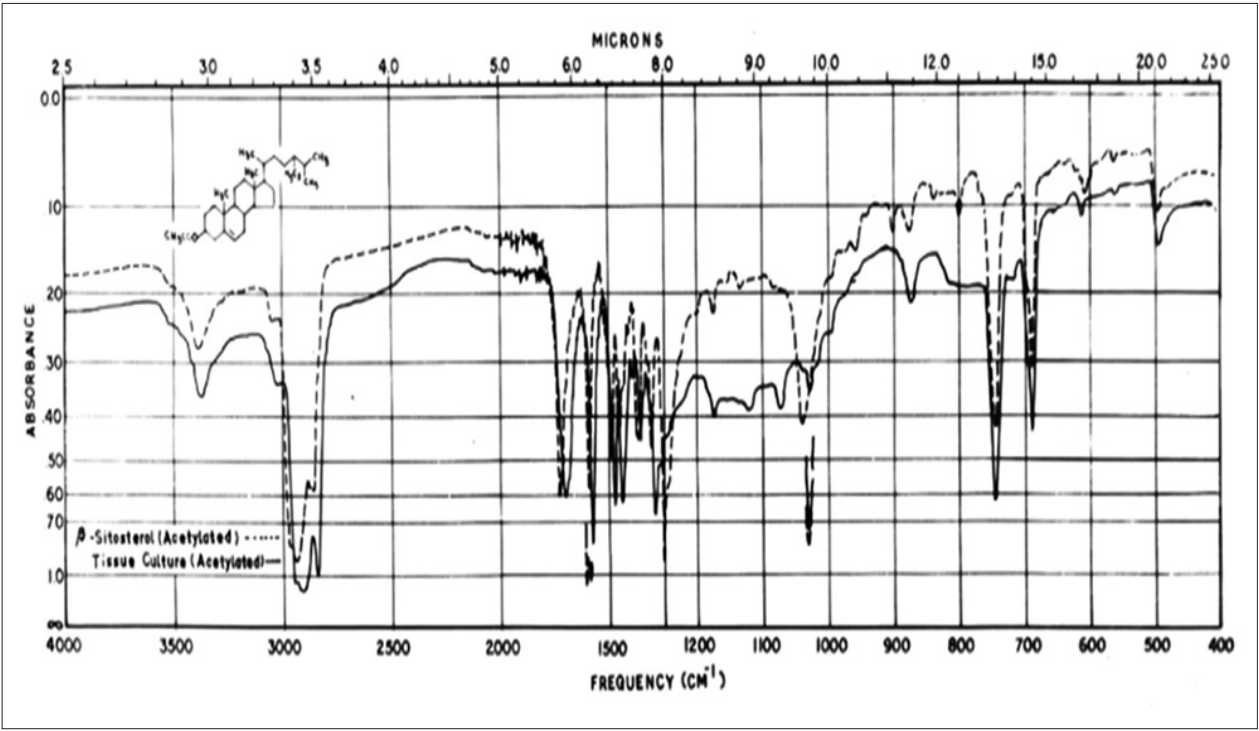

Fig. 2: Infrared spectra of isolated and standard $\beta$-sitosterol 
Determination of antibacterial assay

In vitro antibacterial activity of the phytosterols was studied against Gram-positive and Gram-negative bacterial strains by the agar well diffusion method [18]. Mueller Hinton agar No. 2 (Hi Media, India) was used as the bacteriological medium. The extracts were diluted in benzene at the concentrations of $5 \mathrm{mg} / \mathrm{mL}$. The Mueller Hinton agar was melted and cooled to $48-50^{\circ} \mathrm{C}$ and a standardized inoculum $\left(1.5 \times 10^{8} \mathrm{CFU} / \mathrm{mL}, 0.5 \mathrm{McF}\right.$ arland) was then added aseptically to the molten agar and poured into sterile petri dishes to give a solid plate. Wells were prepared in the seeded agar plates. The test compound $(100 \mu \mathrm{l})$ was introduced in the well $(6 \mathrm{~mm})$. The plates were incubated overnight at $37^{\circ} \mathrm{C}$. The antimicrobial spectrum of the extract was determined for the bacterial species in terms of zone sizes around each well. The diameters of zone of inhibition produced by the agent were compared with those produced by the commercial control antibiotics, streptomycin. For each bacterial strain controls were maintained where pure solvents were used instead of the extract. The control zones were subtracted from the test zones and the resulting zone diameter was measured with antibiotic zone reader to nearest $\mathrm{mm}$. The experiment was performed 3 times to minimize the error, and the mean values are presented.

\section{Determination of antifungal assay}

Anti-fungal activity of the experimental plant was investigated by agar well diffusion method [19]. The fungi strains were subcultured onto potato dextrose agar (Merck, Germany) and, respectively, incubated at $37^{\circ} \mathrm{C}$ for $24 \mathrm{hrs}$ and $25^{\circ} \mathrm{C}$ for $2-5$ days. Suspensions of fungal spores were prepared in sterile PBS and adjusted to a concentration of $10^{6}$ cells $/ \mathrm{mL}$. Dipping a sterile swab into the fungal suspension and rolled on the surface of the agar medium. The plates were dried at room temperature for 15 minutes. Wells of $10 \mathrm{~mm}$ in diameter and about $7 \mathrm{~mm}$ apart were punctured in the culture media using sterile glass tube. $0.1 \mathrm{~mL}$ of several dilutions of fresh extracts was administered to fullness for each well. Plates were incubated at $37^{\circ} \mathrm{C}$. After incubation of 24 hrs bioactivities were determined by measuring the diameter of inhibition zone (in $\mathrm{mm}$ ). All experiments were made in triplicate and means were calculated.

\section{RESULTS AND DISCUSSION}

\section{Phytosterols}

Two sterols were spotted which were common in plant parts on TLC. The $R_{f}$ values of the spots matched with authentic standards and were identified as $\beta$-sitosterol, stigmasterol. Among the various solvent systems tested best results were obtained in the solvent system hexane:acetone (8:2) with $\mathrm{R}_{\mathrm{f}}$ values, namely, $\beta$-sitosterol, 0.89; stigmasterol, 0.83 . The characteristic colors were also developed when TLC plates were sprayed with anisaldehyde reagent ( $\beta$-sitosterol - pink; stigmasterol - purple; and with $50 \%$ sulphuric acid ( $\beta$-sitosterol - purple brown; stigmasterol - gray) corresponding to their authentic samples. The isolated sterols were also identified and characterized with their mp, which also corresponded with those of their respective standards separately ( $\beta$-sitosterol $136-137^{\circ} \mathrm{C}$; stigmasterol; $\left.167-169^{\circ} \mathrm{C}\right)$. The characteristic peaks of IR spectra of isolates $\beta$-sitosterol, stigmasterol) were also found to be superimposable with the IR spectra of reference compounds. However, there are some reports on phytosterols and antimicrobials from other plant sources [20,21].

The main compounds of the phytosterols in B. venusta (L.) were identified using IR and gas chromatography-mass spectroscopy (GC-MS). Sitosterol, stigmasterol were reported by TLC showed in Table 1. A number of 8 spectral peaks were detected in GC-MS analysis. Among these 8 peaks, 2 peaks were identified by MS shown in Table 2 .

\section{Antimicrobial activity of phytosterols}

In the present investigation, both leaf and stem showed potent activity against $E$. coli while rest of the strains were found to be resistant while in case of fungus maximum activity was observed against $F$. oxysporium (Tables 3 and 4) while rest of strains were found to be resistant.

\section{CONCLUSION}

This investigation has given preliminary information to determine the chemical composition of sterols found in B. venusta (L.) using IR and GC-MS. The presence of these bioactive compounds in B. venusta (L.) tends credence to its use by the human community. It also holds for the production of novel drugs with isolation of specific compounds.

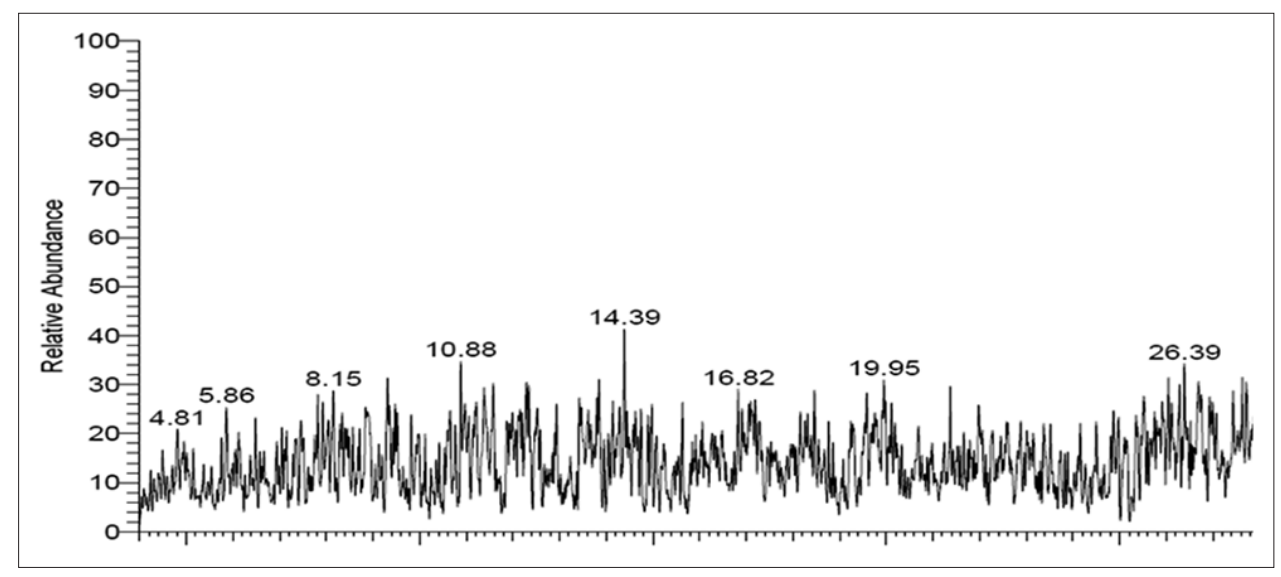

Fig. 3: Gas chromatography-mass spectroscopy profiling of phytosterols

Table 1: Chromatographic behavior and physicochemical characteristics of isolated phytosterols

\begin{tabular}{|c|c|c|c|c|c|c|c|}
\hline \multirow[t]{2}{*}{$\begin{array}{l}\text { Isolated } \\
\text { compounds }\end{array}$} & \multicolumn{3}{|c|}{$R_{\mathrm{f}}$ value } & \multicolumn{2}{|c|}{$\begin{array}{l}\text { Color after } \\
\text { spray }\end{array}$} & \multirow[t]{2}{*}{$\mathrm{MP}\left({ }^{\circ} \mathrm{C}\right)$} & \multirow[t]{2}{*}{ IR spectral peaks (rept.) $v(\mathrm{KBr}) \mathrm{cm}^{-1}$} \\
\hline & $\mathrm{S}_{1}$ & $\mathrm{~S}_{2}$ & $\mathrm{~S}_{3}$ & $\mathrm{R}_{1}$ & $\mathbf{R}_{2}$ & & \\
\hline$\beta$-sitosterol & 0.89 & 0.90 & 0.71 & PU-BN & PK & $136-137$ & $3350(\mathrm{O}-\mathrm{H}), 2830,1665(\mathrm{C}=\mathrm{C}), 1470,1300,1052(\mathrm{C}-\mathrm{O})$ and 880 \\
\hline Stigmasterol & 0.83 & 0.64 & 0.65 & GY & PU & $167-69$ & $3400(\mathrm{O}-\mathrm{H}) .2950,1750,1640(\mathrm{C}=0), 1035(\mathrm{C}-\mathrm{O}), 991,957,935,810$ and 715 \\
\hline
\end{tabular}

$\mathrm{S}_{1}$ : Hexane: acetone (8:2), $\mathrm{S}_{2}$ : Benzene: acetone (2:1), $\mathrm{S}_{3}$ : Benzene: ethyl acetate (3:2), $\mathrm{R}_{1}: 50 \% \mathrm{H}_{2} \mathrm{SO}_{4^{\prime}} \mathrm{R}_{2}:$ Anisaldehyde reagent, BN: Brown, PK: Pink, PU: Purple,

BL: Blue, GY: Gray 
Table 2: GC-MS profiling of phytosterols isolated from bark of B. venusta (L.)

\begin{tabular}{|c|c|c|c|}
\hline Retention time & Area & Area $(\%)$ & Compound name \\
\hline 6.48 & 7519 & 1.40 & Trimethyl(3,3-difluoro-2-propenyl) silane \\
\hline 7.82 & 7891 & 1.47 & Butanoic acid, 3-methyl-3-nitroso-, methyl ester \\
\hline 7.92 & 8644 & 1.61 & Peroxide, dibutyl \\
\hline 8.15 & 12,846 & 2.39 & 1,2-epoxy-5,5-dimethyl-1-phenyl-3-hexyne \\
\hline 8.35 & 7344 & 1.37 & 6,7-dimethyl-triazolo $(4,3$-b $)(1,2,4)$-triazine \\
\hline 8.71 & 5313 & 0.99 & Barbituric acid \\
\hline 9.32 & 20,777 & 3.87 & Cyclopropanecarboxylic acid, 3,4-dichlorophenyl ester \\
\hline 9.48 & 7414 & 1.38 & Silane, 2-butenyltrichloro-,(Z)- \\
\hline 9.53 & 5780 & 1.08 & Acetic acid, anhydride with N-(benzyloxy) benzimidic acid \\
\hline 9.82 & 9164 & 1.71 & Selenium, difluorobis(pentafluoroethyl)- \\
\hline 10.12 & 5458 & 1.02 & 7,8:16,17-dibenzo-1,5,10,14-tetrathiacyclooctadecane \\
\hline 10.65 & 11,767 & 2.19 & 1,1-dimethyl-4-trimethylsilyl-1-silacyclo-2,5-hexadiene \\
\hline 10.88 & 16,390 & 3.05 & Tricyclo[3.3.1.1(3,7)]decane-2,6-dione, 4-amino- \\
\hline 11.21 & 12,417 & 2.31 & Butane, 2-azido-2,3,3-trimethyl- \\
\hline 11.38 & 12,785 & 2.38 & $\mathrm{~N}$-dimethylaminomethyl-isopropylbenzylphosphine \\
\hline 12.30 & 15,130 & 2.82 & Benzamide, 2-[methyl(methylsulfonyl) amino]- \\
\hline 12.35 & 10,006 & 1.86 & 2-ethoxyethyl acrylate \\
\hline 12.94 & 10,934 & 2.04 & Glycine, N-phenyl-N-(trimethylsilyl)-, trimethylsilyl ester \\
\hline 13.42 & 23,779 & 4.43 & 2,2'-dimethyl-6,6'-dinitroazobenzene \\
\hline 13.80 & 6280 & 1.17 & Azetidine, 1-bromo-2-methyl- \\
\hline 13.84 & 9264 & 1.73 & Cycloheptane, methoxy- \\
\hline 14.14 & 7381 & 1.37 & 2-(3'-Phenyl-3'-oxo-propyl)-cyclopentanone \\
\hline 14.39 & 17,448 & 3.25 & $\mathrm{~N}-(3-P y r i d y l)$ cyanoacetamide \\
\hline 14.74 & 12,239 & 2.28 & (Trichlorovinyl) methyldiethoxysilane \\
\hline 14.90 & 11,314 & 2.11 & Cyclopentanecarboxylic acid, 1 -phenyl-,[1,3,4]thiadiazol-2-ylamide \\
\hline 14.97 & 7719 & 1.44 & Benzeneethanamine, $\mathrm{N}$-(2-furanylmethylene)- \\
\hline 15.63 & 10,797 & 2.01 & 2,6-piperazinedione, 4-benzoyl-, dioxime \\
\hline 16.06 & 3895 & 0.73 & 2-propenoic acid, 2-methyl-, 4-formyl-2-methoxyphenyl ester \\
\hline 16.82 & 8116 & 1.51 & Oxirane,(butoxymethyl)- \\
\hline 18.46 & 8765 & 1.63 & 2-propenoic acid, methyl ester \\
\hline 18.76 & 6883 & 1.28 & Iron, tricarbonyl(1,1a, 2,7ü4-1-methylene-2,4,6-cycloheptadiene)- \\
\hline 19.58 & 8085 & 1.51 & E-2-methyl-5-(fur-3-yl)-pent-2-enal \\
\hline 21.37 & 8577 & 1.60 & 1,2-ethanediamine, $\mathrm{N}, \mathrm{N}^{\prime}$-diethyl-N, N'-dimethyl- \\
\hline 24.50 & 5619 & 1.05 & 1-trimethylsilyloxy-n-octene \\
\hline 24.97 & 12,155 & 2.26 & 8-(benzyloxy)-5,6-dihydro-4H-pirazino[3,2,1-jk] carbazole \\
\hline 25.52 & 19,870 & 3.70 & 1,3,4-thiadiazolium, 5-mercapto-2-(4-methylphenyl)-3-phenyl-, hydroxide, inner salt \\
\hline 26.05 & 12,676 & 2.36 & á-d-erythro-hexopyranoside, methyl 2,3-dideoxy-4,6-0-(phenylmethylene)- \\
\hline 26.29 & 19,244 & 3.58 & Methanesulfinamide, 1,1,1-trifluoro-N-(trimethylsilyl)- \\
\hline 26.39 & 13,451 & 2.51 & Phenylacetic acid, 2-methylbutyl ester \\
\hline 26.52 & 4354 & 0.81 & 5-Hydroxy-4-phenylbicyclo[3.3.0]octa-3,6-diene-2,8-dione \\
\hline 26.69 & 24,710 & 4.60 & Cyclotetradecanone oxime \\
\hline 26.74 & 14,108 & 2.63 & Propanedioic acid,(bromomethyl) methyl-, bis(1,1-dimethylethyl) ester \\
\hline 27.43 & 8052 & 1.50 & 1,3-dioxepane, 5,5,6,6-tetrafluoro- \\
\hline 27.63 & 6944 & 1.29 & 1-bromo-7-(tetrahydro-2-pyranyloxy) heptane \\
\hline 27.71 & 14,792 & 2.76 & 2-furancarboxylic acid, 2-methylpropyl ester \\
\hline 27.89 & 5268 & 0.98 & N-benzyl-2-methylaziridine \\
\hline
\end{tabular}

GC-MS: Gas chromatography-mass spectroscopy, B. venusta: Bignonia venusta

Table 3: Antibacterial activity (zone in $\mathrm{mm}$ ) of phytosterols isolated from $B$. venusta

\begin{tabular}{lll}
\hline Bacterial strain & Leaf & Stem \\
\hline B. subtilis & 2 & 2 \\
S. aureus & Nil & Nil \\
E. coli & 8 & 6 \\
S. grisveus & Nil & Nil \\
\hline
\end{tabular}

B. subtilis: Bacillus subtilis, S. aureus: Staphylococcus aureus, E. coli: Escherichia coli, S. grisveus: Streptomyces grisveus, B. venusta: Bignonia venusta

\section{ACKNOWLEDGMENT}

Authors are thankful to UGC-SAP-DRS Phase II for providing financial assistance in the form of a major research project F. No. F.4-10/2015/ DRS II (SAP II) sanctioned to one of the author Mr. Manoj Sharma and special thanks to Prof. Kailash Agrawal (Head, Department of Botany) for helping me with my experiments and providing necessary facilities.
Table 4: Antifungal activity (zones in $\mathrm{mm}$ ) of phytosterols isolated from $B$. venusta

\begin{tabular}{lll}
\hline Fungal strain & Leaf & Stem \\
\hline T. reesei & 4 & 2 \\
F. oxysporium & 8 & 6 \\
P. funicolusum & $\mathrm{Nil}$ & Nil \\
A. niger & $\mathrm{Nil}$ & Nil \\
\hline
\end{tabular}

T. reesei: Trichoderma reesei, F. oxysporium: Fusarium oxysporium,

P. funicolusum: Penicillium funicolusum, A. niger: Aspergillus niger,

B. venusta: Bignonia venusta

\section{REFERENCES}

1. Gbile ZO. Ethno botany, taxonomy and conservation of medicinal plant. In: Sofowora A, editor. The State of Medicinal Plant Research in Nigeria. Nigeria: University of Ibadan Press; 1986. p. 13-29.

2. Moreau RA, Whitaker BD, Hicks KB. Phytosterols, phytostanols, and their conjugates in foods: Structural diversity, quantitative analysis, and 
health-promoting uses. Prog Lipid Res 2002;41(6):457-500.

3. Ostlund RE Jr. Phytosterols in human nutrition. Annu Rev Nutr 2002;22:533-49.

4. Ferreira DT Alvares PS, Houghton PJ, Braz-Filho R. Chemical constituents from roots of Pyrostegia venusta and considerations about its medicinal importance. Química Nova 2000;23(1):42-6.

5. Scalon SP, Vieira MC, Lima AA,Souza CM,Mussury RM. Pregerminative treatments and incubation temperatures on the germination of cipóde - São-João [Pyrostegia venusta(KerGawl.) Miers]-bignoniaceous. Revista Brasileirade PlantasMedicinais 2008;10:37-42.

6. Veloso CC, Bitencourt AD, Cabral LD, Franqui LS, Dias DF, dos Santos MH, et al. Pyrostegia venusta attenuate the sickness behaviour induced by lipopolysaccharide in mice. J Ethnopharmacol 2010;132(1):355-8.

7. Davies DJ. Origins and evolution of antibiotic resistance. Microbial Mol Bio Rev 2010;74(3):417-33.

8. Saranraj P, Sivasakthi S. Medicinal plants and its antimicrobial properties: A view. Global J Pharmacol 2014;8(3):316-27.

9. Bako SP, Bakfur MJ, John I, Bala EI. Ethno medicinal and phytochemicals profile of some Savanna plant species in Nigeria. Int J Bot 2005;1(2):147-50.

10. Robbers JE, Speedie MK, Tyler VE. Pharmacognosy. New York: Williams \& Wilkins; 1996

11. Iwu MM, Duncan RA, Okunji CO. New antimicrobials of plant origin. In: Janick J, editor. Perspectives on New Crops and New Uses. Alexandria, VA: ASHS Press Alexandria Virginia; 1996. p. 457-62.
12. Trease G, Evans W. Pharmacognosy. Aberdeen, Great. Britain: University Press; 1972. p. 161-3.

13. Abreu AC, McBain AJ, Simoes M. Plants as sources of new antimicrobials and resistance modifying agents. Nat Prod Rep 2012;29:1007-21.

14. Kaul B, Staba EJ. Dioscorea tissue cultures. I. Biosynthesis and isolation of diosgenin from Dioscorea deltoidea callus and suspension cells. Lloydia 1968;31:171-9.

15. Fazli FR, Hardman R. The spice fenugreek (Trigonellafoenumgraecum); its commercial variety of seed as a source of dysgenic. Trop Sci 1968; 10:66-78

16. Heble MR, Narayanaswami S, Chadha MS. Diosgenin and betasitosterol: Isolation from Solanum xanthocarpum tissue cultures. Science 1968;161(3846):1145.

17. Bennett RD, Heftmann E. Thin-layer chromatography of steroidal sapogenins. J Chromatogr 1962;9:353-8.

18. Perez C, Paul M, Bazerque P. An antibiotic assay by the agar-well diffusion method. Acta Biol Med Exp 1990;15:113-5.

19. Shadidi B, Aghighi S, Karimi NA. Antibacterial and antifungal survey in plants used in indigenous herbal-medicine of South East Regions of Iran. J Biol Sci 2005;4:405-12.

20. Roopalatha UC, Nair VM. Phytochemical analysis of successive reextracts of the leaves of Moringa oleifera lam. Int J Pharm Pharm Sci 2013;5:629-34.

21. Ismail K, Abdullah S, Chong K. Screening for potential antimicrobial compounds from Ganoderma boninense against selected food borne and skin disease pathogens. Int J Pharm Pharm Sci 2014;6(2):771-4 